\title{
Dietary fat intake and red blood cell fatty acid composition of children and women from three different geographical areas in South Africa
}

Rosalyn Ford, Mieke Faber, Ernesta Kunneke and Cornelius M. Smuts

\begin{abstract}
Dietary fat intake, particularly the type of fat, is reflected in the red blood cell (RBC) fatty acid (FA) profile and is vital in growth, development and health maintenance. The FA profile (\%wt/wt) of RBC membrane phospholipids (as determined by gas chromatography) and dietary intake (as determined by 24 $h$ recall) was assessed in 2-6 y old South African children and their caregivers randomly selected from three communities, i.e. an urban Northern Cape community (urban-NC; $\mathrm{n}=104$ ), an urban coastal Western Cape community (urban-WC; $\mathbf{n}=93$ ) and a rural Limpopo Province community (rural-LP; $\mathbf{n}=102$ ). Mean RBC FA values across groups were compared using ANOVA and Bonferroni post-hoc test while controlling for age and gender (children); median dietary intake values were compared using a Kruskal-Wallis test. Dietary intakes for total fat, saturated FAs and polyunsaturated FAs were higher in the two urban areas compared to the rural area. Total fat intake in rural-LP, and omega-3 FA dietary intake in all three areas were lower than the South African adopted guidelines. Dietary SFA intake in both urban areas was higher than recommended by South African guidelines; this was reflected in the RBC membrane FA profile. Rural-LP children had the lowest intake of omega-3 and omega-6 FAs yet presented with the highest RBC docosahexaenoic acid (DHA) profile and highest arachidonic acid percentage. Although differences observed in dietary fat intake between the two urban and the rural area were reflected in the RBC membrane total phospholipid FA profile, the lowest total fat and $\alpha-$ linolenic acid (ALA) intake by rural children that presented with the highest RBC DHA profile warrants further investigation.
\end{abstract}

\section{Introduction}

The fatty acid (FA) composition of human red blood cells (RBC) and plasma is greatly influenced by different dietary patterns and especially the type of fats consumed [1]. The type of dietary fat ultimately affects the individual's health, contributing towards either disease prevention or promotion, and 
also child development [1,2]. Dietary fat intake recommendations throughout the human life cycle are based on the requirements to meet essential fatty acid (EFA) needs, to support neurodevelopment and cardiovascular health, and to prevent degenerative diseases [2]. Certain RBC FAs have been shown to be influenced by FA intake, and this measure is used as a good indicator of a longer term FA intake [3].

The quality of fat consumed in the diet is largely determined by the quantities of polyunsaturated fatty acids (PUFA), thus omega- 6 and omega-3 fatty FAs consumed [4]. The importance and supply of docosahexaenoic acid (DHA) and eicosapentaenoic acid (EPA) by the diet throughout the life cycle has increasingly gained more interest and evidence relates health benefits of these FAs to fish intake. Research suggests that this is due to the consumption of pre-formed EPA and DHA in the fish [5,6]. These FAs play vital roles in cell membrane functioning, brain and nervous system development and functioning, and in the manufacture of eicosanoids [7]. DHA is also considered as a conditional EFA, especially during the early developmental years [8].

Even though a-linolenic acid (ALA), found in food sources other than fish, is a precursor of EPA and DHA, it is questionable if the conversion in the human body is sufficient to meet the need [7,9]. Also, a diet high in linoleic acid (LA), thus more than $10 \%$ of total energy intake, reduces the conversion of ALA to EPA and DHA [10,11]. Therefore, the habitual diet and balance between LA and ALA consumption are important factors in determining the long chain polyunsaturated fatty acid profile of RBC membranes, particularly in non-fish eaters $[8,10]$.

There is a concern that for low income communities that do not consume fish regularly, particularly those situated inland [10], omega-3 FA intake is possibly low, with possible increased intakes of omega- 6 FAs $[8,12]$. However, limited literature is available from developing countries on the FA status, dietary intake and composition, particularly regarding omega- 3 and omega- 6 FAs $[10]$.

South Africa is a widely diverse country with many varied income, living conditions and resources. In addition, South Africa has diverse ethnic groups with different traditional eating patterns [13]. These eating patterns could result in different FA intakes. The more industrialised lifestyle and current 'Western diet' that many South Africans particularly in urban areas, already follow or are transitioning towards, has resulted in an increased consumption of saturated, omega-6 PUFA and trans FAs $[13,14]$. In contrast to this, the dietary habits of rural living South African communities are described as more prudent, lower in fat, with a higher intake of starch-rich staple foods [13]. The South African National Food Consumption Survey found milk (56.3\%), meat 
and offal $(47.9 \%)$ and vegetable fats $(36.8 \%)$ to be the three main food groups contributing fat to the diet of children 1-5 years of age. Fish was consumed by $7.6 \%$ of children [15]. The pattern in adults were found to be similar, as meat and offal (57.4\%), vegetable fats and oil (47.9\%) and milk (30.6\%) were the food groups which supplied fat to the diet [16]. However, specific data on EFA intake and prevalence of EFA deficiency for the South African population is lacking.

The aim of this study was to assess the FA profile (\%) of RBC membrane phospholipids and the dietary fat intake of South African preschool children and women from three different geographical areas, each with known distinct dietary patterns. The FA profile and possible relations between the RBC FA profile and dietary intake were examined.

\section{Study population and methods \\ 2.1 Study population}

This cross-sectional study forms part of a sub-study nested within a parent study that aimed to determine the vitamin A intake and status of South African children and that of their primary caregivers, located in four geographical sites, and over a wide range of dietary patterns [17]. Three of the four geographical areas were selected for the current nested study as these were assumed to have the most distinct differences in eating patterns between groups. The study was done in an urban community in the Northern Cape (urban-NC), an urban coastal community in the Western Cape (urban-WC) and a rural community in Limpopo Province (rural-LP). The urban-NC area is situated in the Karoo where sheep farming is common and mutton consumption is frequent. The urban-WC area is a coastal community and fish consumption particularly that of fresh fish, was thought to be higher. The ruralLP area was predicted to have a more prudent diet pattern with a lower fat intake and a more frequent consumption of green leafy vegetables [18].

For the parent study in which this study was nested, 200 randomly selected preschool children as well as their respective caregivers were recruited from each geographical area, as described in Faber et al. [17]. If more than one child in the household fitted the age range, one of them was randomly selected. If the mother was unable to attend, a female caregiver preferably from the household, was recruited. The measurements of all geographical areas were taken in 2011.

The parent study showed that $490 \%$ of households in all three areas had access to electricity; nearly all households had a flush toilet in the two urban areas and a pit toilet in the rural area, respectively. Most households in the two urban areas had access to tap water, versus only $13.7 \%$ in rural-LP, where most of the households had to fetch water from the river or natural spring or 
had to buy from a water truck. While electricity was mostly used for cooking in the two urban areas, wood (mostly as an open fire inside the dwelling) and gas/paraffin were used in the rural area [17].

For the current study, approximately 100 children aged 2-6 years and their caregivers per area, for whom all the measurements were completed for both the caregiver and the child, were included.

Anthropometric measurements were taken as described in Faber et al. [17].

\subsection{Biochemical analysis, blood sampling}

A nursing sister collected a $10 \mathrm{ml}$ non-fasting blood sample by antecubital venipuncture from each child and woman and transferred it into EDTA anticoagulant tubes. The blood was then centrifuged at $3500 \mathrm{rpm}$ for $10 \mathrm{~min}$ where after the plasma was harvested. The red blood cells were washed three times with normal saline and $\mathrm{RBC}$ samples were stored at $-80{ }^{\circ} \mathrm{C}$ until analysed within 3 months after collection.

Total phospholipid FA extraction and analysis were done following an adapted method of Folch et al. [19] as described by Baumgartner et al. [20]. The total lipid extraction with chloroform/ methanol (2:1; v/v) containing butylated hydroxytoluene was done using $300 \mathrm{ml}$ of the thawed $\mathrm{RBC}$ sample.

The total phospholipid fraction was separated from the neutral lipids by using pre-coated thin layer chromatography silica gel 60 plates $(10 \mathrm{~cm} \times 20 \mathrm{~cm}$; Merck) that were developed in a filter paper lined separation tank containing diethyl ether, petroleum ether and acetic acid (30:90:1; v-v:v) as developing agent. The total phospholipid fraction was removed by scraping it off the plate through a funnel into a clean Teflon-lined screw-capped test tube.

Once $2 \mathrm{ml}$ of trans-methylating solution (methanol:sulphuric acid; 95:5; v-v) had been added to the phospholipid sample, it was incubated at $70^{\circ} \mathrm{C}$ for 120 min, yielding the FA methyl esters (FAMEs). FAMEs were extracted with 2 $\mathrm{ml}$ hexane and $1 \mathrm{ml}$ distilled water.

The hexane phase containing the FAMEs was evaporated under nitrogen at 45 ${ }^{\circ} \mathrm{C}$. After this, $45 \mu \mathrm{l}$ of hexane was added and mixed well to re-dissolve the FAMEs. The resulting FAMEs were analysed by using quadrupole (QP) Gas Chromatography-electron impact- mass spectrometry (GC-EI-MS) on an Agilent Technologies 7890A gas chromatography (GC) System equipped with an Agilent Technologies 5975C VL mass selective detector. A BPX 70 capillary column $(60 \mathrm{~m}$; $0.25 \mathrm{~mm} 0.25 \mathrm{~mm}$; SGE Analytic Sciences) was used in the GC separation of the FAMEs. The GC inlet and MS line were maintained at a temperature of $280{ }^{\circ} \mathrm{C}$ and $230{ }^{\circ} \mathrm{C}$, respectively. Helium at $197.86 \mathrm{kPa}$ was the carrier gas with a flow rate of 
$1.3 \mathrm{ml} / \mathrm{min}$. The injection volume of the sample solution was $1 \mu \mathrm{l}$ using a split ratio of 1:1. The oven temperature was programmed at $130^{\circ} \mathrm{C}$ to $240^{\circ} \mathrm{C}$, rose from $130{ }^{\circ} \mathrm{C}$ to $200{ }^{\circ} \mathrm{C}$ at $2{ }^{\circ} \mathrm{C} / \mathrm{min}$, was held isothermally at $220{ }^{\circ} \mathrm{C}$ for 5 min, it was increased by $10{ }^{\circ} \mathrm{C} / \mathrm{min}$ to $240{ }^{\circ} \mathrm{C}$, where it was retained for 5 min. The complete analysis took $53 \mathrm{~min}$. QP-GC-MS with $70 \mathrm{eV}$ electron impact functioned in full scan acquisition mode. All mass spectra were acquired over the $\mathrm{m} / \mathrm{z}$ range of 50-500. FAMEs were quantified with the use of the selected ion extraction method based on the response of two selected diagnostic ions.

The chromatographic data was analysed using mass selective detector ChemStation software (Agilent G1701EA version E.02.00.493). The FAME peaks were identified and calibrated against a standard reference mixture of 26 FAMEs (Nu-Chek-Prep, Elysian, Minnesota, USA) and three single FAME standards (Larodan Fine Chemicals AB, Malmö, Sweden). Concentrations were read from a calibration curve that was produced for each FAME. Relative percentages of the FAs $(\% \mathrm{w} / \mathrm{w})$ were calculated by taking the concentration of a given FA derivative as a percentage of the total concentration of all FAs identified in the sample.

\subsection{Dietary intake}

A $24 \mathrm{~h}$ dietary recall was done for each child and his/her caregiver by trained fieldworkers who interviewed the caregiver in the local language. Household utensils, plastic food models, three dimensional sponge models, standardised photographs, dry oats and a measuring cup were used to describe the portion sizes. The MRC Food Quantities Manual was used to convert the food intake from household measures into weight [21]. All the dietary information from the $24 \mathrm{~h}$ recall was converted into macro- and micronutrients with the use of SAS software package (version 9 . 1; SAS Institute Inc., Cary, NC) using the SAFOODS20oo database. Information on the respective brand names of margarines used by the household was used to identify the most commonly consumed soft and hard margarine in each of the study sites. The FA values, as obtained from the manufacturers, for these specific margarines were used in the nutrient analysis of the dietary intake data.

A short questionnaire focusing on the use and brand name of oils, fats and fish consumed by the household was completed for each caregiver with the assistance of a trained fieldworker. The data received from the questionnaire provided information on dietary sources of FAs.

\subsection{Statistical analysis}

The data was first cleaned and checked for outliers. RBC membrane total phospholipid FA profile (\%) values that were three times the standard deviation (SD) above and below the mean were considered outliers and removed. 
Children and women who reported in the $24 \mathrm{~h}$ recall, consumption of less than $650 \mathrm{kcal}$ and $1000 \mathrm{kcal}$, respectively, were considered under-reporters and were therefore not included in the dietary intake analysis. Analysis of the data was performed using the IBM Statistical Package for Social Sciences (IBM SPSS 20.0 for Windows). Normality of the data was firstly determined by observing histograms and performing the Shapiro-Wilks test. Dietary data is presented as the median with the inter-quartile ranges (IQR) as it was not normally distributed. In order to compare the dietary data between the geographical areas, the Kruskal-Wallis test was done. The RBC membrane total phospholipid FA profile (\%) data were determined to be normally distributed and thus presented as a mean with the SD. An analysis of variance (ANOVA) test followed by a Bonferroni post-hoc test was done to compare the different groups. In the children, age and gender were controlled for and in the women, age was controlled for. A P-value of 00.05 was used to indicate that the data was significantly different. Categorical data is reported as a percentage.

\subsection{Ethical aspects}

Ethical approval was granted by the Ethics Committee of the South African Medical Research Council (EC1O-O2O). The study was conducted according to the Declaration of Helsinki. Permission from local councillors and community leaders was acquired. Written informed consent was obtained from the mother or legal guardian allowing for the collection of all the information.

\section{Results}

The number of subjects (child and caregiver) from each community who completed each required test including giving a blood sample, completing the $24 \mathrm{~h}$ recall and the socio-demographic questionnaire came to 104 from urban-NC, 93 from urban-WC and 102 from rural-LP. Two red blood cell FA samples of the children and one from a caregiver were excluded as the samples had oxidised. Anthropometric measurements of the subjects are presented in Table 1. No significant differences were seen between the groups except for the children's weight in urban-NC and urban-WC.

\subsection{Dietary intake}

Fifteen foods mostly consumed by children during the $24 \mathrm{~h}$ recall period are presented in Table 2. Fat-containing foods mostly consumed by the children were salty snacks (reported for $57.3 \%$ of the children during the recall period) chicken (44.9\%), margarine (42.7\%) and meat (39.3\%) in urban-NC; salty snacks (65.9\%), margarine (60.4\%), fresh milk (56\%) and meat (38.5\%) in urban-WC; and chicken (44.3\%), milk powder (27.8\%), margarine (19.0\%) and salty snacks (17.7\%) in rural-LP. Oil was reportedly consumed by $36.0 \%$ of urban-NC, 33.0\% of urban-WC and $16.5 \%$ of rural-LP children $(\mathrm{P}=0.002)$. 
The median reported energy, macronutrient, cholesterol and FA daily intakes of children and women are presented in Tables 3 and 4, respectively. Children's total fat, SFA, MUFA, PUFA, total omega-3, trans fat, AA, ALA, EPA and DHA reported intakes were significantly higher for urban-WC and urban-NC, compared to rural-LP. Reported dietary energy, carbohydrate, protein, total omega-6 and LA intakes were found to be significantly higher in urban-WC's children than the other two areas.

Women from rural-LP had the lowest reported fat intake, and this was also reflected in the individual FAs. Urban-WC and urban-NC women had the highest reported fat intake which was also reflected in the individual FAs with the exception of omega-6 and LA intake, which were significantly higher in urbanWC compared to urban-NC and rural LP.

Table 5 shows fish consumption as reported in the $24 \mathrm{~h}$ dietary recall for children and women. Rural-LP children ate a significantly smaller amount of fish compared to urban-NC and urban-WC children. For the women, no significant differences were reported in fish intake between the different communities. The types of spreads and fish commonly consumed by the communities, as determined by questionnaire, are presented in Table 6.

\subsection{RBC membrane total phospholipid FA profile}

The mean percentage and ratios of RBC membrane total phospholipid FA profile (\%) for children and women are presented in Tables 7 and 8, respectively. For each site, gender differences for RBC membrane FAs were tested; no significant differences were found, except for AA in urban-WC (boys: $13.94 \%$ and girls: $15.28 \%, \mathrm{P}=0.014$ ).

Table 1

Anthropometric measurements of children and women.

\begin{tabular}{llll}
\hline & $\begin{array}{l}\text { Urban-NC } \\
(n=104)\end{array}$ & $\begin{array}{l}\text { Urban-WC } \\
(n=93)\end{array}$ & $\begin{array}{l}\text { Rural-LP } \\
(n=102)\end{array}$ \\
\hline Boys/girls (\%) & $51.9 / 48.1$ & $53.8 / 46.2$ & $53.9 / 46.1$ \\
Child's age, years (mean, SD) & $3.5(1.1)$ & $3.7(1.2)$ & $3.5(1.0)$ \\
Child stunted (\%) & 40.4 & 16.5 & 16.7 \\
Woman's age, years (mean, SD) $^{\mathrm{a}}$ & $32.8(10.0)$ & $32.9(11.0)$ & $34.8(13.8)$ \\
Woman's BMI, (mean, SD) & $27.0(7.7)$ & $28.7(8.2)$ & $26.6(5.7)$ \\
\hline
\end{tabular}

BMI, body mass index (BMI $\geq 25-30=$ overweight [22]); LP, Limpopo Province; NC, Northern Cape; WC, Western Cape.

${ }^{a}$ Height-for-age $<-2$ SD of the median of the reference population [23]. 
Table 2

Fifteen foods mostly consumed by children during the $24 \mathrm{~h}$ recall period.

\begin{tabular}{|c|c|c|c|c|c|c|}
\hline \multirow[t]{2}{*}{ Ranking } & \multicolumn{2}{|l|}{ Urban-NC $(n=89)$} & \multicolumn{2}{|l|}{ Urban-WC $(n=91)$} & \multicolumn{2}{|l|}{ Rural-LP $(n=79)$} \\
\hline & Food & $\%$ & Food & $\%$ & Food & $\%$ \\
\hline 1. & Sugar (mostly white) & 84.3 & Sugar (mostly white) & 83.5 & Maizemeal porridge & 96.2 \\
\hline 2. & Bread (excl homemade) & 67.4 & Bread & 79.1 & Sugar (mostly white) & 72.2 \\
\hline 3. & Maizemeal porridge & 60.7 & Rice & 67.0 & Tea (incl rooibos) & 65.8 \\
\hline 4. & Salty snacks (niknaks/crisps) & 57.3 & Salty snacks (niknaks/crisps) & 65.9 & Bread (excl homemade) & 50.6 \\
\hline 5. & Tea (incl rooibos) & 56.2 & Margarine & 60.4 & Vegetables & 50.6 \\
\hline 6. & Rice & 51.7 & Fresh milk (mostly full cream) & 56.0 & Chicken & 44.3 \\
\hline 7. & Chicken & 44.9 & Tea (incl rooibos) & 52.7 & Milk powder (mostly full cream) & 27.8 \\
\hline 8. & Margarine & 42.7 & Vegetables & 47.3 & Cooked porridge, other than maizemeal & 21.5 \\
\hline 9. & Vegetables & 41.6 & Roots and tubers (mostly potato) & 46.2 & Fruit & 21.5 \\
\hline 10. & Meat (beef, mutton, pork) & 39.3 & Cold drinks & 45.1 & Cold drinks & 21.5 \\
\hline 11. & Roots and tubers (mostly potato) & 39.3 & Sweets/chocolate/confectionary & 45.1 & Margarine & 19.0 \\
\hline 12. & Fresh milk (mostly full cream) & 34.8 & Meat (beef, mutton, pork) & 38.5 & Salty snacks (niknaks/crisps) & 17.7 \\
\hline 13. & Sweets/chocolate/confectionary & 38.2 & Chicken & 36.3 & Roots and tubers (mostly potato) & 17.7 \\
\hline 14. & Oil & 36.0 & Breakfast cereals & 34.1 & Oil & 16.5 \\
\hline \multirow[t]{2}{*}{15.} & Cold drinks & 31.5 & Oil & 33.0 & Non-dairy creamer & 15.2 \\
\hline & & & Fruit & 33.0 & Amasi (fermented milk) & 15.2 \\
\hline
\end{tabular}

LP, Limpopo Province; NC, Northern Cape; WC, Western Cape; consumption of less than 650 kcal were considered under-reporters and were excluded.

Table 3

Median reported energy, macronutrient, cholesterol and fatty acid daily intake of children from the three study areas.

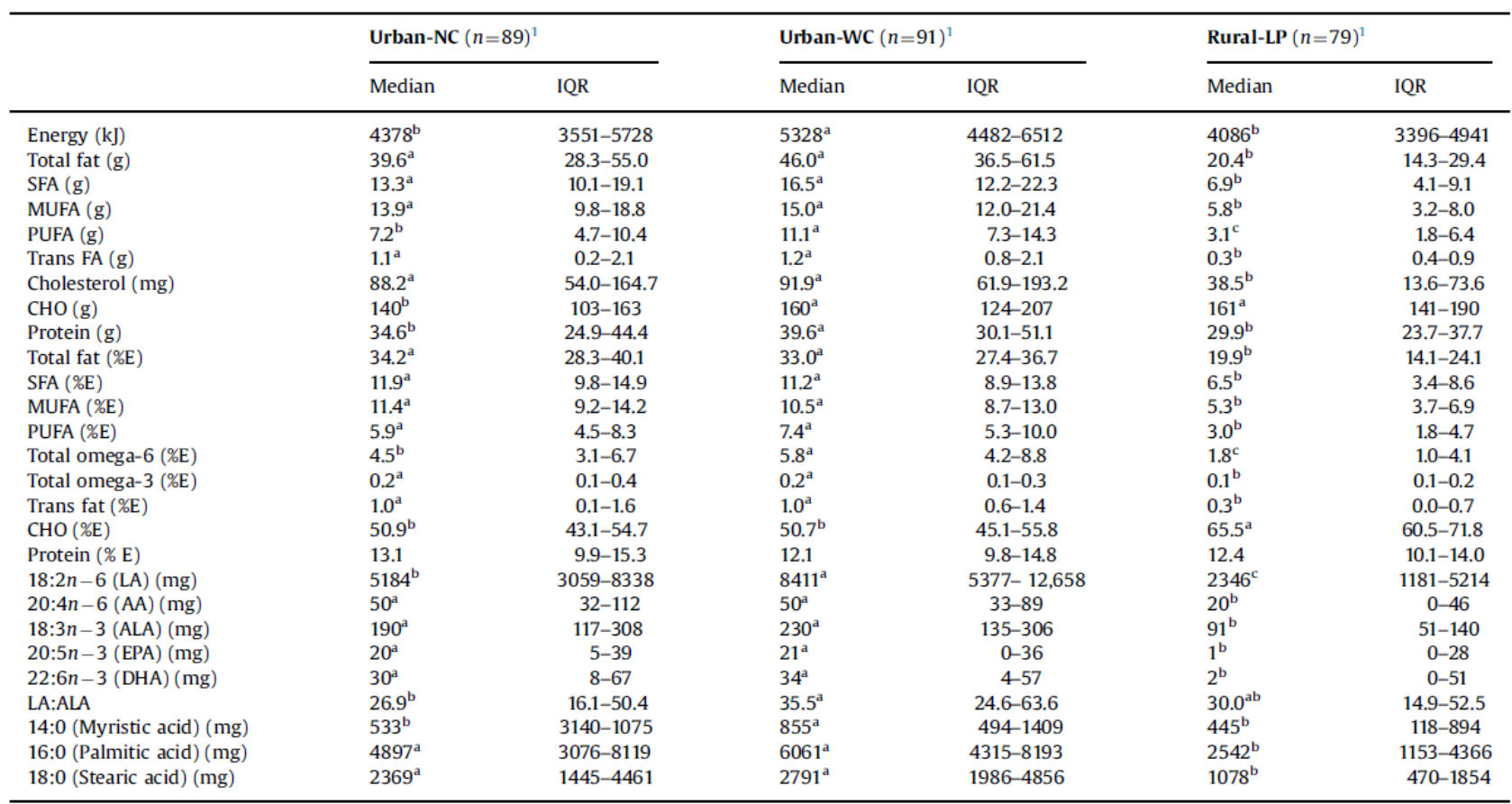

NC, Northern Cape; WC, Western Cape; LP, Limpopo Province; IQR, Inter-quartile range; kJ, kilojoule; SFA, saturated fatty acids; MUFA, monounsaturated fatty acids; PUFA, polyunsaturated fatty acids; CHO, carbohydrate; LA, linoleic acid; AA, arachidonic acid; ALA, alpha-linolenic acid; EPA, eicosapentaenoic acid; DHA, docosahexaenoic acid. Medians in a row with different superscripts differ significantly, $P<0.05$; 'a' was assigned to the highest value.

${ }^{1} n$ is the number of dietary intakes after outliers have been removed; consumption of less than 650 kcal was considered under-reporters and was excluded.

As a large percentage of children attended crèche, receiving a different meal than that of the caregiver, correlations were not done between the children and women. The RBC SFA profile for children differed significantly across the three sites (P O O.001), with the highest values in children from urban-NC, followed by urban-WC and then rural-LP. The opposite results were seen in the children's RBC membrane PUFA profile, with children in rural-LP having the highest percentage (40\%), followed by urban-WC and then urban-NC, each differing significantly ( $\mathrm{P}$ o o.001). The same trend is observed in the children's 
omega-6 and omega-3 percentages with children in rural-LP having significantly higher values than those in urban-WC, which had significantly higher values than children in urban-NC (Table 7). The SFA profile percentage of the RBC membrane phospholipids of the women of rural-LP was significantly lower than those in the other two sites ( $\mathrm{P}$ O O.001). Rural-LP women had significantly higher PUFA, omega-6 and AA RBC membrane total phospholipid FA profiles than those in the other two sites; urban-NC women had significantly higher percentages of trans FAs and EPA, and a significantly lower percentage of LA than women in urban-WC and rural-LP (Table 8).

Table 4

Median reported daily energy, macronutrient, cholesterol and fatty acid intake of women from the three study areas.

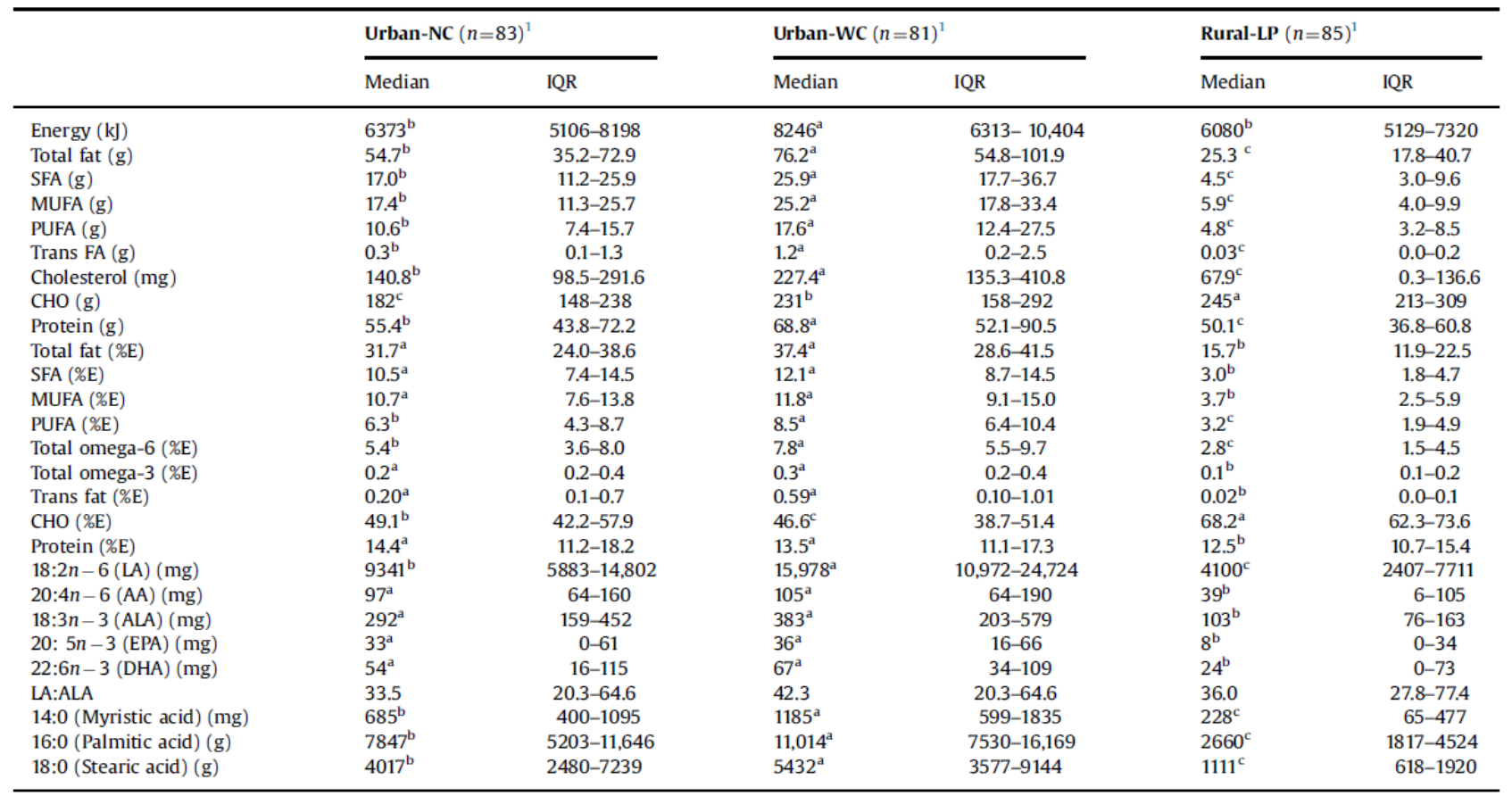

NC, Northern Cape; WC, Western Cape; LP, Limpopo Province; IOR, Inter-quartile range; kJ, kilojoule; SFA, saturated fatty acids; MUFA, monounsaturated fatty acids; PUFA, polyunsaturated fatty acids; CHO, carbohydrate; LA, linoleic acid; AA, arachidonic acid; ALA, alpha-linolenic acid; EPA, eicosapentaenoic acid; DHA, docosahexaenoic acid. Medians in a row with different superscripts differ significantly, $P<0.5$; 'a' was assigned to the highest value;

${ }^{1} n$ is the number of dietary intakes after outliers have been removed; consumption of less than 1000 kcal was considered under-reporters and was excluded. 
Table 5

Fish consumption as reported in the $24 \mathrm{~h}$ dietary recall for children and women.

\begin{tabular}{lccc}
\hline & Urban-NC & Urban-WC & Rural-LP \\
\hline $\begin{array}{l}\text { Children } \\
\text { Reported fish consumption (\%) }\end{array}$ & $(n=89)$ & $(n=91)$ & $(n=79)$ \\
$\begin{array}{l}\text { Median (IQR) amount of fish eaten } \\
(\mathrm{g} / \text { consumer) }\end{array}$ & $60(36-75)^{\mathrm{ab}}$ & $60(55-80)^{\mathrm{a}}$ & $30(18-45)^{\mathrm{b}}$ \\
$\begin{array}{l}\text { Women } \\
\text { Reported fish consumption (\%) }\end{array}$ & $(n=83)$ & $(n=81)$ & $(n=85)$ \\
$\begin{array}{l}\text { Median (IQR) amount of fish eaten } \\
(\mathrm{g} / \text { consumer) }\end{array}$ & $90(54-148)$ & $120(80-150)$ & $66(60-121)$ \\
\hline
\end{tabular}

NC, Northern Cape; WC, Western Cape; LP, Limpopo Province; IQR, inter-quartile range

Medians in a row with different superscripts differ significantly, $P<0.05$.

\section{Table 6}

Types of spreads and fish frequently used or consumed by the household and women in the three study sites, as determined by questionnaire.

\begin{tabular}{|c|c|c|c|}
\hline & $\begin{array}{l}\text { Urban-NC } \\
(n=104) \\
\%\end{array}$ & $\begin{array}{l}\text { Urban-WC } \\
(n=93) \\
\%\end{array}$ & $\begin{array}{l}\text { Rural-LP } \\
(n=102) \\
\%\end{array}$ \\
\hline \multicolumn{4}{|c|}{$\begin{array}{l}\text { Type of spread used on bread by } \\
\text { household }\end{array}$} \\
\hline Hard margarine & 62 & 47 & 61 \\
\hline Soft margarine & 33 & 40 & 30 \\
\hline Butter & 1 & 5 & 2 \\
\hline Do not use & 5 & 4 & 7 \\
\hline \multicolumn{4}{|c|}{ Most common fish consumed by women ${ }^{1}$} \\
\hline Pilchards & 69 & 0 & 94 \\
\hline Snoek & 23 & 61 & 0 \\
\hline Hake & 3 & 16 & 3 \\
\hline Hottentot & 0 & 9 & 0 \\
\hline Sardine/karabau & 0 & 0 & 1 \\
\hline
\end{tabular}

NC, Northern Cape; WC, Western Cape; LP, Limpopo Province.

${ }^{1}$ The top three types of fish named in questionnaire are presented; as the fish commonly consumed by the women is very similar than that for the children, only the results for the women are given. 


\section{D iscussion}

Three communities from different geographical areas were included in this study with the aim of investigating the RBC membrane total phospholipid FA profile against the background of different dietary intakes by the three communities. The main findings showed that the three communities were distinct in terms of dietary fat intake and RBC membrane total phospholipid FA profile. The greatest distinction was between rural-LP and the two urban communities. Children from rural-LP had the lowest ALA, EPA and DHA intakes yet presented the highest RBC DHA profile. The lower dietary intake of SFA in children and women in rural-LP is reflected in their lower RBC SFA percentage and higher RBC PUFA percentage and RBC PUFA/SFA ratio.

Results from this study support previous findings that in South Africa rural communities generally eat a more traditional diet typically lower in fat and higher in carbohydrates, whereas the urban populations are reportedly changing to a more 'Westernised diet' with a higher fat intake [13]. Total fat as a percentage of total energy $(\% \mathrm{E})$ for women in the two urban areas was above the South African adopted recommendations of $\mathrm{O} 30 \% \mathrm{E}[4,24]$, whereas children and women from rural-LP had a low total fat intake (20\% and $16 \%$, respectively) which put them at risk of negative outcomes resulting from a low fat intake. 
Table 7

Mean percentage and ratios of red blood cell membrane total phospholipid fatty acid profile of the children in the three areas.

\begin{tabular}{|c|c|c|c|c|c|c|}
\hline \multirow[t]{2}{*}{ Fatty acids } & \multicolumn{2}{|c|}{$\begin{array}{l}\text { Urban-NC } \\
(n=99-104)^{1}\end{array}$} & \multicolumn{2}{|c|}{$\begin{array}{l}\text { Urban-WC } \\
(n=86-92)^{1}\end{array}$} & \multicolumn{2}{|c|}{$\begin{array}{l}\text { Rural-LP } \\
(n=94-101)^{1}\end{array}$} \\
\hline & Mean & SD & Mean & SD & Mean & SD \\
\hline SFA & $52.22^{\mathrm{a}}$ & 8.22 & $47.95^{b}$ & 3.23 & $44.95^{c}$ & 1.53 \\
\hline MUFA & $15.28^{\mathrm{a}}$ & 1.78 & $14.78^{\mathrm{a}}$ & 1.36 & $14.05^{\mathrm{b}}$ & 1.13 \\
\hline PUFA $^{2}$ & $32.03^{c}$ & 8.81 & $36.99^{b}$ & 3.55 & $40.65^{a}$ & 1.89 \\
\hline Omega- $6^{3}$ & $26.60^{c}$ & 6.59 & $30.61^{\mathrm{b}}$ & 3.05 & $33.71^{a}$ & 2.01 \\
\hline Omega- $3^{4}$ & $5.32^{c}$ & 2.47 & $6.07^{\mathrm{b}}$ & 1.41 & $6.78^{\mathrm{a}}$ & 0.96 \\
\hline Trans & $0.44^{\mathrm{a}}$ & 0.27 & $0.22^{\mathrm{b}}$ & 0.12 & $0.19^{\mathrm{b}}$ & 0.12 \\
\hline $18: 2 n-6(\mathrm{LA})$ & $10.09^{b}$ & 1.55 & $11.04^{\mathrm{a}}$ & 1.11 & $10.46^{\mathrm{b}}$ & 1.29 \\
\hline $20: 4 n-6(\mathrm{AA})$ & $12.83^{\mathrm{c}}$ & 4.43 & $14.62^{\mathrm{b}}$ & 2.61 & $17.51^{\mathrm{a}}$ & 1.36 \\
\hline $22: 5 n-3$ & $0.44^{\mathrm{c}}$ & 0.24 & $0.62^{\mathrm{b}}$ & 0.20 & $1.03^{\mathrm{a}}$ & 0.29 \\
\hline $18: 3 n-3($ ALA $)$ & $0.03^{c}$ & 0.02 & $0.04^{\mathrm{b}}$ & 0.02 & $0.05^{\mathrm{a}}$ & 0.02 \\
\hline $20: 5 n-3$ (EPA) & 0.30 & 0.18 & 0.31 & 0.16 & 0.31 & 0.16 \\
\hline $22: 6 n-3(\mathrm{DHA})$ & $3.48^{\mathrm{b}}$ & 1.79 & $4.22^{\mathrm{a}}$ & 1.24 & $4.63^{\mathrm{a}}$ & 0.71 \\
\hline 14:0 (Myristic acid) & $0.23^{\mathrm{ab}}$ & 0.09 & $0.23^{\mathrm{a}}$ & 0.083 & $0.20^{\mathrm{b}}$ & 0.08 \\
\hline 16:0 (Palmitic acid) & $27.15^{\mathrm{a}}$ & 4.65 & $24.16^{\mathrm{b}}$ & 2.23 & $23.06^{\mathrm{c}}$ & 1.52 \\
\hline 18:0 (Stearic acid) & $18.47^{\mathrm{a}}$ & 2.02 & $17.66^{\mathrm{b}}$ & 1.13 & $16.92^{c}$ & 1.15 \\
\hline $\mathrm{AA} / \mathrm{EPA}$ & $59.06^{\mathrm{b}}$ & 52.03 & $56.61^{\mathrm{b}}$ & 24.53 & $69.38^{a}$ & 32.95 \\
\hline EPA/ALA & $11.50^{\mathrm{a}}$ & 8.35 & $8.69^{a}$ & 4.47 & $6.74^{\mathrm{b}}$ & 3.67 \\
\hline DHA/EPA & $13.58^{\mathrm{b}}$ & 9.04 & $15.30^{\mathrm{a}}$ & 4.93 & $17.58^{\mathrm{a}}$ & 7.01 \\
\hline DHA/ALA & 134 & 110 & 124 & 68 & 102 & 38 \\
\hline $\mathrm{AA} / \mathrm{DHA}$ & $4.37^{\mathrm{a}}$ & 1.73 & $3.70^{\mathrm{b}}$ & 0.90 & $3.88^{\mathrm{ab}}$ & 0.67 \\
\hline LA/ALA & $499^{\mathrm{a}}$ & 686 & 325 & 181 & $246^{\mathrm{b}}$ & 435 \\
\hline Omega-6/Omega-3 & 5.97 & 2.28 & 5.20 & 1.06 & 5.09 & 0.86 \\
\hline PUFA/SFA & $0.66^{\mathrm{b}}$ & 0.24 & $0.78^{\mathrm{b}}$ & 0.11 & $0.91^{\mathrm{a}}$ & 0.06 \\
\hline
\end{tabular}

NC, Northern Cape; WC, Western Cape; LP, Limpopo Province; SFA, saturated fatty acids; MUFA, monounsaturated fatty acids; PUFA, polyunsaturated fatty acids; LA, linoleic acid; AA, arachidonic acid; ALA, alpha-linolenic acid; EPA, eicosapentaenoic acid; DHA, docosahexaenoic acid.

Controlled for age and gender; means in a row with different superscripts differ significantly, $P<0.05$; 'a' was assigned to the highest value.

${ }^{1}$ A range for $n$ is provided as various identified fatty acids were excluded as they were outliers.

2 PUFA percentage includes: the sum of omega- 6 and omega- 3 fatty acid percentages.

${ }^{3}$ Omega-6 percentage includes: $18: 2 n-6 ; 18: 3 n-6 ; 20: 2 n-6 ; 20: 3 n-6$; $20: 4 n-6 ; 22: 2 n-6 ; 22: 4 n-6 ; 22: 5 n-6$.

${ }^{4}$ Omega-3 percentage includes: $18: 3 n-3 ; 18: 4 n-3 ; 20: 3 n-3 ; 20: 5 n-3$; $22: 5 n-3 ; 22: 6 n-3$. 
Table 8

Mean percentage and ratios of red blood cell membrane total phospholipid fatty acid profile of women from the three study areas.

\begin{tabular}{|c|c|c|c|c|c|c|}
\hline \multirow[t]{2}{*}{ Fatty acids } & \multicolumn{2}{|c|}{$\begin{array}{l}\text { Urban-NC } \\
(n=99-104)^{1}\end{array}$} & \multicolumn{2}{|c|}{$\begin{array}{l}\text { Urban-WC } \\
(n=86-92)^{1}\end{array}$} & \multicolumn{2}{|c|}{$\begin{array}{l}\text { Rural-LP } \\
(n=94-101)^{1}\end{array}$} \\
\hline & Mean & SD & Mean & SD & Mean & SD \\
\hline SFA & $47.83^{\mathrm{a}}$ & 4.15 & $47.19^{a}$ & 2.49 & $45.05^{\mathrm{b}}$ & 2.66 \\
\hline MUFA & $16.17^{\mathrm{a}}$ & 2.00 & $15.46^{\mathrm{b}}$ & 1.44 & $14.59^{\mathrm{c}}$ & 1.44 \\
\hline PUFA $^{2}$ & $35.80^{c}$ & 4.11 & $37.15^{\mathrm{b}}$ & 2.75 & $40.16^{\mathrm{a}}$ & 3.09 \\
\hline Omega- $6^{3}$ & $28.72^{\mathrm{c}}$ & 3.19 & $30.03^{\mathrm{b}}$ & 2.51 & $33.31^{\mathrm{a}}$ & 2.82 \\
\hline Omega- $3^{4}$ & 6.90 & 1.60 & 6.84 & 1.54 & 6.52 & 1.32 \\
\hline Trans & $0.34^{\mathrm{a}}$ & 0.19 & $0.19^{\mathrm{b}}$ & 0.09 & $0.17^{\mathrm{b}}$ & 0.13 \\
\hline $18: 2 n-6(\mathrm{LA})$ & $9.26^{\mathrm{b}}$ & 1.67 & $10.25^{\mathrm{a}}$ & 1.41 & $9.91^{\mathrm{a}}$ & 1.52 \\
\hline $20: 4 n-6(\mathrm{AA})$ & $15.18^{\mathrm{b}}$ & 2.18 & $14.94^{\mathrm{b}}$ & 1.90 & $17.16^{\mathrm{a}}$ & 2.19 \\
\hline $20: 5 n-6$ (DPA) & $0.42^{\mathrm{b}}$ & 0.16 & $0.48^{\mathrm{b}}$ & 0.15 & $0.83^{\mathrm{a}}$ & 0.26 \\
\hline $18: 3 n-3$ (ALA) & 0.04 & 0.02 & 0.04 & 0.02 & 0.04 & 0.02 \\
\hline $20: 5 n-3(\mathrm{EPA})$ & $0.51^{\mathrm{a}}$ & 0.21 & $0.43^{\mathrm{b}}$ & 0.24 & $0.27^{c}$ & 0.12 \\
\hline $22: 6 n-3(\mathrm{DHA})$ & 4.33 & 1.31 & 4.63 & 1.21 & 4.39 & 1.05 \\
\hline $\begin{array}{l}\text { 14:0 (Myristic } \\
\text { acid) }\end{array}$ & $0.23^{\mathrm{a}}$ & 0.09 & $0.23^{\mathrm{a}}$ & 0.07 & $0.193^{\mathrm{b}}$ & 0.07 \\
\hline $\begin{array}{l}\text { 16:0 (Palmitic } \\
\text { acid) }\end{array}$ & $25.16^{\mathrm{a}}$ & 2.73 & $24.12^{\mathrm{b}}$ & 1.93 & $23.58^{b}$ & 2.59 \\
\hline $\begin{array}{l}\text { 18:0 (Stearic } \\
\text { acid) }\end{array}$ & 17.32 & 1.91 & 17.38 & 1.08 & 16.91 & 1.46 \\
\hline AA/EPA & $32.43^{\mathrm{b}}$ & 12.55 & $40.64^{\mathrm{b}}$ & 16.43 & $71.84^{\mathrm{a}}$ & 27.60 \\
\hline EPA/ALA & $15.13^{\mathrm{a}}$ & 8.46 & $11.23^{\mathrm{b}}$ & 5.83 & $6.99^{c}$ & 3.53 \\
\hline DHA/EPA & $8.95^{c}$ & 2.81 & $11.85^{\mathrm{b}}$ & 3.91 & $17.86^{\mathrm{a}}$ & 5.69 \\
\hline DHA/ALA & 131 & 74 & 122 & 54 & 115 & 48 \\
\hline AA/DHA & $3.65^{\mathrm{b}}$ & 0.87 & $3.43^{\mathrm{b}}$ & 0.96 & $4.00^{\mathrm{a}}$ & 0.74 \\
\hline LA/ALA & 305 & 192 & 278 & 121 & 262 & 128 \\
\hline $\begin{array}{l}\text { Omega-6/Ome- } \\
\text { ga-3 }\end{array}$ & $4.23^{\mathrm{b}}$ & 0.77 & $4.49^{\mathrm{b}}$ & 1.00 & $5.15^{\mathrm{a}}$ & 0.89 \\
\hline PUFA/SFA & $0.76^{\mathrm{b}}$ & 0.15 & $0.79^{\mathrm{b}}$ & 0.09 & $0.91^{\mathrm{a}}$ & 0.08 \\
\hline
\end{tabular}

NC, Northern Cape; WC, Western Cape; LP, Limpopo Province; SFA, saturated fatty acids; MUFA, monounsaturated fatty acids; PUFA, polyunsaturated fatty acids; LA, linoleic acid; AA, arachidonic acid; ALA, alpha-linolenic acid; EPA, eicosapentaenoic acid; DHA, docosahexaenoic acid

Controlled for age; means in a row with different superscripts differ significantly, $P<0.05$; 'a' was assigned to the highest value.

${ }^{1}$ A range for $n$ is provided as various identified fatty acids were excluded as they were outliers.

2 PUFA percentage includes: the sum of omega- 6 and omega- 3 fatty acid percentages.

${ }^{3}$ Omega-6 percentage includes: $18: 2 n-6 ; 18: 3 n-6 ; 20: 2 n-6 ; 20: 3 n-6$; $20: 4 n-6 ; 22: 2 n-6 ; 22: 4 n-6 ; 22: 5 n-6$.

${ }^{4}$ Omega-3 percentage includes: $18: 3 n-3 ; 18: 4 n-3 ; 20: 3 n-3 ; 20: 5 n-3$; $22: 5 n-3 ; 22: 6 n-3$. 
In children, low fat $(25-30 \% \mathrm{E})$ intake has been shown to be associated with growth failure and a lower intake of fat soluble vitamins [2]. In adults a minimum fat intake of $15 \% \mathrm{E}$ is required to ensure sufficient energy and EFA intake, and to facilitate fat soluble vitamin absorption [25].

For the current study, when investigating the type or quality of fat, it was found that dietary SFA consumed by children and women in both urban-NC $(12 \% \mathrm{E}$ and $11 \% \mathrm{E}$, respectively) and urban-WC (11\%E and $12 \% \mathrm{E}$, respectively) was above the recommended $\mathrm{O} 10 \% \mathrm{E}$ [24]. The higher SFA consumption found in urban-NC and urban-WC could possibly be explained by the higher number of meat (beef, mutton or pork) consumers in these areas. Harika et al. [26,27] examined the dietary fat intake of children and adults from 40 different countries; South Africa was reported to have a total fat and SFA intake of $23 \% \mathrm{E}$ and $6 \% \mathrm{E}$, respectively, in children and $28 \% \mathrm{E}$ and $8.6 \% \mathrm{E}$, respectively, for adults. However, as the results from our study show, different areas within South Africa have significantly different fat intake. Richter et al. [28] found similar differences between urban and rural fat intakes but also an overall low omega-3 FA intake.

None of the ALA median intakes met the recommended adequate intake (AI) levels of $700-900 \mathrm{mg} / \mathrm{d}$ for the children and $1100 \mathrm{mg} /$ day for the women [29,30]. The urban-WC children and women had significantly higher LA (8411 mg and $15978 \mathrm{mg}$, respectively) intakes which made it the only area to meet the AI (700-1000 $\mathrm{mg}$ /day for children and $1200 \mathrm{mg} /$ day for women) for LA [30]. The higher LA intake in urban-WC could possibly be explained by the higher consumption of margarine and oil; with $60.4 \%$ and $33 \%$ of children having consumed margarine and oil, respectively, during the recall period. The soft tub margarines used by $40 \%$ of urban-WC households, mostly have a higher LA and lower SFA content than the brick margarines [31]. A higher dietary omega-6 (LA) proportion can influence the conversion rate of ALA to EPA and DHA [8]; and omega-3 FAs in all communities were already being consumed in lower than recommended quantities (700-900 $\mathrm{mg} /$ day for the children and $1100 \mathrm{mg} /$ day for women) [30].

The median EPA and DHA intakes did not reach the AI level of $100-200 \mathrm{mg} / \mathrm{d}$ for the children and 250-500 $\mathrm{mg} / \mathrm{d}$ for the women for any of the three areas $[29,30]$. As increased fish consumption is recommended as the most effective way of increasing preformed EPA and DHA levels [4], it was expected that urban-WC, being a coastal community, would have a higher fish intake and therefore a significantly higher EPA and DHA intake and RBC EPA and DHA percentage. This was however not the case as shown. South African recommendations state that approximately $100 \mathrm{~g}$ of fish should be eaten twice a week, depending on the fat content of the fish [4]. As a single $24 \mathrm{~h}$ dietary intake was done, it is not known if this recommendation was met by subjects. The type of fish commonly consumed by children and women in 
urban-WC was snoek, followed by hake. The sum of the EPA and DHA content in Snoek (1030 $\mathrm{mg} / 100 \mathrm{~g}$ ) and hake $(518 \mathrm{mg} / 100 \mathrm{~g}$ ) is, however, lower than that for pilchards (1480 mg/100 g) [32]. Snoek and hake were the more commonly consumed type of fish in urban-NC and rural-LP possibly contributing to the lower than expected EPA and DHA levels in urban-WC.

The higher RBC PUFA content in both the children and women in rural-LP may contribute to increased membrane fluidity, resulting in positive health implications [33]. A significantly higher RBC AA content and RBC AA/EPA ratio were found in both the children and women in rural-LP compared to urban-NC and urban-WC. AA and EPA in cell membranes serve as precursors for the production of eicosanoids, which is dependent on the concentration of AA and EPA present [34]. AA derived eicosanoids mainly have pro-inflammatory functions, while EPA has anti-inflammatory functions [34]. An imbalance of pro-inflammatory eicosanoids can result in thrombosis, kidney disease, inflammation, asthma and other inflammation related diseases [34]. The AA and EPA content and thus eicosanoid production in membranes can be altered by dietary changes $[29,35]$ and it would be prudent that for all three areas women and children increase their ALA, EPA and DHA dietary intake. This could be done by promoting either an increased frequency or bigger portion size of fatty fish consumption. Canned pilchards would also be accessible to inland communities in South Africa.

Urban-NC's RBC EPA content was significantly higher than the other two communities and a significantly higher EPA/ALA ratio was observed. This could possibly be due to an increased intake of dietary EPA; however this was not reflected in dietary data that was collected using a $24 \mathrm{~h}$ recall. Alternatively, urban-NC women may have had a higher conversion rate of ALA to EPA or the conversion rate in urban-WC and rural-LP women was decreased due to the significantly higher percentage RBC LA. A higher LA concentration leads to a low ALA to EPA conversion rate due to the limited $\Delta-6$ desaturase availability for ALA $[36,37]$.

Rural-LP children consumed the lowest amount of each omega-3 FA, yet still presented with the highest RBC DHA profile. Raatz et al. [38] reported in a study where 17 females were placed on a low fat (20\%E) diet for 8 weeks, significant increases in plasma AA and DHA, particularly in comparison to the high fat $(45 \% \mathrm{E})$ diet. In another study by Raatz et al. [39] it was reported that 10 subjects placed on a low fat diet $(20 \% \mathrm{E})$ presented with significant increases in plasma omega-3 FA profiles, particularly DHA and EPA, and that a high fat diet $(45 \% \mathrm{E})$ was associated with increased omega- $6 \mathrm{FA}$ profiles. The changes as a result of the high and low fat diets in both studies were attributed to the decreased and increased (respectively), availability of desaturase enzymes involved in the elongation, desaturation pathway $[38,39]$. 
The significantly higher RBC AA profiles of rural-LP's women and children could be a result of not just dietary influence but also genetic influences. A study comparing African American FA profiles to Europeans both consuming Westernised diets, found that African American's had higher AA percentages than the Europeans, with its precursors LA and $\gamma$-linolenic acid (GLA) in both groups being similar [40]. Participants in urban-WC and urban-NC were predominantly mixed ancestry, whereas participants in rural-LP were all black Africans. This may also explain the higher RBC DHA in rural-LP children as LA and ALA utilise the same enzyme system for conversion to AA and DHA, respectively. The higher RBC membrane SFA profile in urban-NC and urban-WC women and children reflects the significantly higher SFA intakes. The significantly higher LA intake in urban-WC is also reflected in the significantly higher RBC membrane LA percentage.

Kuipers et al. [41] reported lower RBC omega-3, EPA and DHA percentages for a group of Tanzanian women from a low fish eating community; but higher for women from a high fish eating community. The RBC ALA profile of the women in our study was far below that of the Tanzanian women from both the low and high fish eating communities. RBC total omega-6 (31.9\%), LA (9.55\%) and AA (16.1\%) in Tanzanian women in a low fish eating community were more comparable to our study's women.

Blanchet et al. [42] reported on Canadian Inuit children (11-53 months) on a more westernized diet than the traditional high fish diet. The Inuit children had lower RBC membrane DHA and AA; and higher ALA, EPA and LA compared to the children in our study. The omega-3 (5.53\%) profile for the Inuit children was between the omega-3 profiles for children in urban-NC (5.32\%) and urban-WC (6.07\%), and the omega-6 (30.11\%) profile for the Inuit children was similar to that of the urban-WC children (30.61\%).

A second $24 \mathrm{~h}$ dietary recall would have increased the reliability and validity of the dietary intake results in our study, and might have better reflected habitual intake, but could not be done due to logistical challenges. Therefore, correlation coefficients for the association between RBC membrane FA profiles and dietary intake were not calculated. It is recommended that in future studies such as this one where a follow up $24 \mathrm{~h}$ recall is logistically challenging, a quantified food frequency questionnaire be used to assess habitual dietary intake. However, despite the fact that a single $24 \mathrm{~h}$ recall is not necessarily an indication of habitual intake, the findings of the $24 \mathrm{~h}$ recall in the current study were confirmed with the FA biomarker data in our study. Before analysis of the dietary intake data, the FA profiles for hard and soft margarine in the food composition database were revised based on the 
specific brand of margarine mostly consumed in each study area. This strengthened the dietary intake data with regards to the estimated FA intake.

\section{Conclusion}

Vast differences were observed in dietary fat intake and RBC membrane phospholipid FA profiles in the urban-NC and urban-WC children and women in comparison to those in rural-LP. Urban-NC and urban-WC children and women had a higher SFA intake which is reflected in the higher RBC membrane phospholipid SFA profile. This raises concerns of future risks of coronary heart disease for both the children and women. In all three communities, insufficient intakes of the parent EFAs LA and ALA were observed, with the exception of LA intake in urban-WC children and women. In combination with the low EFA intake, a low EPA and DHA intake was reported for all communities. Rural-LP children had the lowest EFA intake but reflected the highest RBC DHA profile, probably suggesting a more efficient conversion from ALA to DHA. As South Africa simultaneously deals with the double burden of over and under nutrition, fat recommendations should be set with care. More focus should be placed on recommending the replacement of dietary SFA with PUFA particularly omega-3 FA and the increased consumption of fatty fish.

\section{Summary}

The fatty acid (FA) profile of red blood cell (RBC) membrane phospholipids and dietary intake was assessed in South African children (2-6 y old) and women randomly selected from two urban and one rural area. Dietary intake of total fat, saturated FA (SFA) and polyunsaturated FA was significantly higher in the two urban areas compared to the rural area. Total fat intake in the rural area and omega-3 FA dietary intake in all three areas were lower than recommended by South African FA intake guidelines. In the urban areas, SFA intake was higher than South African FA recommended intakes and this was reflected in the $\mathrm{RBC}$ membrane FA profile. Rural children had the lowest intake of omega- 3 and omega- 6 FAs yet presented with the highest RBC docosahexaenoic acid profile as well as the highest arachidonic acid percentage; this warrants further investigation. Overall, differences in dietary fat intake between the two urban and the rural area were reflected in the RBC membrane total phospholipid FA profile.

\section{Conflicts of interest}

The authors have no conflict of interest.

\section{Author's contribution}

R.F.: RBC membrane fatty acid analysis; analyses, compilation and interpretation of data; drafted the manuscript. M.F.: Initiated and conceptualised the parent study; data collection; revision of paper. E.K.: Dietary coding, analysis and interpretation; revision of paper. C.M.S.: 
Conceptualised this sub-study; oversee data collection, analysis and interpretation; revision of paper. All authors read and approved the final version of the paper.

\section{Financial support}

The parent study was supported by a grant received from SIGHT AND LIFE Basel Switzerland.

\section{Acknowledgements}

We would like to thank the South African Medical Research Council for parenting the study. Thank you to all children and mothers/caregivers who participated in the study. We would also like to thank the lab technicians at NWU for assisting in all the fatty acid analysis. 


\section{References}

[1] A.J. Hulbert, N. Turner, L.H. Storlien, P.L. Else, Dietary fats and membrane function: implications for metabolism and disease, Biol. Rev. 80 (2005) 155-169.

[2] R. Uauy, Dietary fat quality for optimal health and well-being: overview of recommendations, Ann. Nutr. Metab. 54 (S1) (2009) 2-7.

[3] Q. Sun, J. Ma, H. Campos, S.E. Hankinson, F.B. Hu, Comparison between plasma and erythrocyte fatty acid content as biomarkers of fatty acid intake in US women, Am. J. Clin. Nutr. 86 (2007) 74-81.

[4] C.M. Smuts, P. Wolmarans, The importance of the quality or type of fat in the diet: a food-based dietary guideline for South Africa, S. Afr. J. Clin. Nutr. 26 (3) (2013) S87-S99.

[5] C.H.S. Ruxton, S.C. Reed, M.J.A. Simpson, K.J. Millington, The health benefits of omega-3 polyunsaturated fatty acids: a review of evidence, J. Human. Nutr. Diet. 20 (2007) 275-285.

[6] F.B. Hu, L. Bronner, W.C. Willett, M.J. Stampfer, K.M. Rexrode, C.M. Albert, D. Hunter, J.E. Manson, Fish and omega-3 fatty acid intake and risk of coronary heart disease in women, J. Am. Med. Assoc. 287 (14) (2002) 18151821.

[7] B.C. Davis, P.M. Kris-Etherton, Achieving optimal essential fatty acid status in vegetarians: current knowledge and practical implications, Am. J. Clin. Nutr. 78 (Suppl. 3) (2003) S640-S646.

[8] R.A. Gibson, B. Muhlhausler, M. Makrides, Conversion of linoleic acid and alpha-linolenic acid to long-chain polyunsaturated fatty acids (LCPUFAs), with a focus on pregnancy, lactation and the first 2 years of life, Matern. Child. Nutr. 7 (Suppl. 2) (2011) S17-S26.

[9] L.M. Arterburn, E.B. Hall, H. Oken, Distribution, interconversion, and dose response of n-3 fatty acids in humans, Am. J. Clin. Nutr. 83 (2006) 1467S-1476S. [10] A. Briend, K. Dewey, G.A. Reinhart, Fatty acid status in early life in low-income countries - overview of the situation, policy and research priorities, Matern. Child. Nutr. 7 (Suppl. 2) (2011) S141-S148.

[11] G.C. Burdge, P.C. Calder, a-Linolenic acid metabolism in adult humans: the effects of gender and age on conversion to longer chain polyunsaturated fatty acids, Eur. J. Lipid Sci. Tech. 107 (2005) 426-439.

[12] A.M. Prentice, A.A. Paul, Fat and energy needs of children in developing countries, Am. J. Clin. Nutr. 72 (5) (2000) 1253S-1265S.

[13] N. Steyn, D. Bradshaw, R. Norman, J. Joubert, M. Schneier, K. Steyn, Dietary Changes and the Health Transition in South Africa: Implications for Health Policy, South African Medical Research Council, Cape Town, 2006.

[14] H.H. Vorster, A. Kruger, B. Margetts, The nutrition transition in Africa: can it be steered into a more positive direction, Nutrients 3 (2011) $429-441$.

[15] D. Labadarios, N. Steyn, E. Maunder, U. MacIntyre, R. Swart, G. Gericke, 
J. Huskisson, A. Dannhauser, H.H. Vorster, A.E. Nesamvuni, J.H. Nel, The national food consumption survey (NFCS): South Africa, 1999, Public Health Nutr. 8 (5) (2005) 533-543.

[16] J.H. Nel, N.P. Steyn, Report on South African food consumption studies undertaken amongst different population groups (1983-2000): average intakes of foods most commonly consumed, Medical Research Council, 2002. 〈http:// www.mrc.Ac.za/chronic/foodstudies.htm〉 (Date accessed: 19.11.14).

[17] M. Faber, P.J. van Jaarsveld, E. Kunneke, H.S. Kruger, S. Schoeman, M.E. van Stuijvenberg, Vitamin A and anthropometric status of South African preschool children from four areas with known distinct eating patterns, Nutrition 31 (2015) 64-71.

[18] N. Steyn, S. Burger, K. Monyeki, M. Alberts, G. Nthangeni, Seasonal variation in dietary intake of the adult population of Dikgale, S. Afr. J. Clin. Nutr. 14 (4) (2001) 140-145.

[19] J. Folch, M. Lees, S.G.H. Stanley, A simple method for the isolation and purification of total lipides from animal tissues, J. Biol. Chem. 226 (1957) 497-509.

[20] J. Baumgartner, C.M. Smuts, L. Malan, J. Kvalsvig, M.E. van Stuijvenberg, R. F. Hurrell, M.B. Zimmermann, Effects of iron and $n-3$ fatty acid supplementation, alone and in combination, on cognition in school children: a randomized, double-blind, placebo-controlled intervention in South Africa, Am. J. Clin. Nutr. 96 (2012) 1327-1338.

[21] M.L. Langenhoven, P.J. Conradie, P. Wolmarans, M. Faber, MRC Food Quantities Manual, Second ed., Medical Research Counci, Parow, 1991.

[22] World Health Organization, Obesity: Preventing and Managing the Global Epidemic. Report of a WHO Consultation in Obesity, Geneva, June 30, World Health Organization, Geneva, 1998.

[23] World Health Organization. Child growth standards. Length/heightfor-age, weight-for-age, weight-for-length, weight-for-height and body mass index for age. Methods and Development. Geneva, World Health Organization, 2006.

[24] C. Diekman, I. Elmadfa, B. Koletzko, P. Puska, R. Uauy, Summary statement of the international expert meeting: health significance of fat quality of the diet, Ann. Nutr. Metab. 54 (Suppl. 1) (2009) S39-S40.

[25] E. Jéquier, Response to and range of acceptable fat intake in adults, Eur. J. Clin. Nutr. 53 (Suppl. 1) (1999) S88-S93.

[26] R.K. Harika, M.C. Cosgrove, S.J. Osendarp, P. Verhoef, P.L. Zock, Fatty acid intakes of children and adolescents are not in line with the dietary intake recommendations for future cardiovascular health: a systematic review of dietary intake data from thirty countries, Br. J. Nutr. 106 (3) (2011) 307-316.

[27] R.K. Harika, A. Eilander, M. Alssem, S.J.M. Osendarp, P.L. Zock, Intake of fatty acids in general populations worldwide does not meet dietary 
recommendations to prevent coronary heart disease: a systematic review of data from 40 countries, Ann. Nutr. Metab. 63 (2013) 229-238.

[28] M. Richter, J. Baumgartner, E. Wentzel-Viljoen, C.M. Smuts, Different dietary fatty acids are associated with blood lipids in healthy South African men and women: the PURE study, Int. J. Cardiol. 172 (2) (2014) 368-374.

[29] Food and Agriculture Organization (FAO) of the United Nations, Fats and Fatty Acids in Human Nutrition: Report of an Expert Consultation, 2010. 〈http:// www.fao.org/docrep/o13/i1953e/i1953eoo.pdf) (Date accessed: 30.10.13).

[30] National Research Council, Dietary Reference Intakes for Energy, Carbohydrate, Fiber, Fat, Fatty Acids, Cholesterol, Protein, and Amino Acids (Macronutrients), 2005 . 〈http://www.nap.edu/catalog.php?record_id 1/4 10490〉 (Date accessed: 17.07.13).

[31] C. Albrecht, A Comparative Study of the Fatty Acid Composition of Forty Margarines Available in South Africa, Cancer Association of South Africa (CANSA), 2010. 〈http://www.drcarlalbrecht.com/documents/2013/Compara tive-study-onfatty-acids-in-margarines.pdf) (Date accessed 28.04.14).

[32] M. Kruger, M.L. Langenhoven, M. Faber, Fatty Acid and Amino Acid Composition Tables, South African Medical Research Council, Parow, 1992.

[33] P.C. Calder, Mechanisms of action of ( $\mathrm{n}-3$ ) fatty acids, J. Nutr. 142 (2012) 592S-599S.

[34] P.C. Calder, Polyunsaturated fatty acids and inflammatory processes: new twists in an old tale, Biochimie 91 (2009) 791-795.

[35] T.M. Trebble, S.A. Wootton, E.A. Miles, M. Mullee, N.K. Arden, A.B. Ballinger, M. A. Stroud, G.C. Burdge, P.C. Calder, Prostaglandin E2 production and $\mathrm{T}$ cell function after fish-oil supplementation: response to antioxidant cosupplementation, Am. J. Clin. Nutr. 78 (2003) 376-382.

[36] G.C. Burdge, Y.E. Finnegan, A.M. Minihane, C.M. Williams, S.A. Wootton, Effect of altered dietary $n-3$ fatty acid intake upon plasma lipid fatty acid composition, conversion of [13C] $\alpha$-linolenic acid to longer-chain fatty acids and partitioning towards $\beta$-oxidation in older men, Br. J. Nutr. 90 (2003) 311-321.

[37] N. Hussein, E. Ah-Sing, P. Wilkinson, C. Leach, B.A. Griffin, D.J. Millward, Long-chain conversion of $[13 \mathrm{C}]$ linoleic acid and a-linolenic acid in response to marked changes in their dietary intake in men, J. Lipid Res. 46 (2004) 269-280.

[38] S.K. Raatz, L.R. Young, M.J. Picklo Sr, E.W. Sauter, W. Qin, M.S. Kurzer, Total dietary fat and fatty acid content modifies plasma phospholipid fatty acids, desaturase activity indices, and urinary prostaglandin $\mathrm{E}$ in women, Nutr. Res. 32 (2012) 1-7. 
[39] S.K. Raatz, D. Bibus, W. Thomas, P. Kris-Etherton, Total fat intake modifies plasma fatty acid composition in humans, J. Nutr. 131 (2001) 213-234.

[40] S. Sergeant, C.E. Hugenschmidt, M.E. Rudock, J.T. Ziegler, P. Ivester, H. C. Ainsworth, D. Vaidya, L.D. Case, C.D. Langefeld, B.I. Freedman, D.W. Bowden, R.A. Mathias, F.H. Chilton, Differences in arachidonic acid levels and fatty acid desaturase (FADS) gene variants in African Americans and European Americans with diabetes or the metabolic syndrome, Br. J. Nutr. 107 (4) (2012) 547-555.

[41] R.S. Kuipers, M.F. Luxwolda, W.S. Sango, G. Kwesigabo, J.D.A. DijckBrouwer, F. A.J. Muskiet, Postdelivery changes in maternal and infant erythrocyte fatty acids in 3 populations differing in fresh water fish intakes, Prostaglandins Leukot. Essent. Fat. Acids 85 (2011) 387-397.

[42] R. Blanchet, J. Lauziére, D. Gagné, C. Vézina, P. Ayotte, H.T. O’Brien, Usual dietary fatty acid intakes and red-blood-cell membrane fatty acid composition in Inuit children attending child-care centres in Nunavik, northern Québec, Canada, Public Health Nutr. 17 (2) (2014) 2844-2852. 